\title{
Alcohol and injury in Poland: review and training recommendations
}

\author{
Piotr Wozniak • Rebecca Cunningham - Sonia Kamat • \\ Kristen L. Barry • Frederic C. Blow • \\ Andrzej S. Zawadzki
}

Received: 14 July 2009 / Accepted: 10 February 2010 /Published online: 13 May 2010

(C) Springer-Verlag London Ltd 2010

\begin{abstract}
Background Alcohol plays a significant role in accidents, injuries, and their outcomes. According to the World Health Organization (WHO), there are 76.3 million people with alcohol use disorders worldwide; in 2000, 1.8 million deaths and loss of 58.3 million disability-adjusted life years were attributed to alcohol.

Methods Although the association between alcohol consumption and trauma-related morbidity and mortality is well-documented, particularly in the US, there is much less
\end{abstract}

At the time this paper was written, Dr. Wozniak was a Fogarty International Injury and Alcohol Fellow with the University of Michigan's Department of Psychiatry

The views expressed in this paper are those of the author(s) and not those of the editors, editorial board or publisher.

\section{P. Wozniak}

Gdansk Medical Center Emergency Department,

Gdansk, Poland

R. Cunningham $\cdot$ S. Kamat

Department of Emergency Medicine, University of Michigan,

Ann Arbor, MI, USA

K. L. Barry $\cdot$ F. C. Blow

Department of Psychiatry and Department of Veterans Affairs

National Serious Mental Illness Treatment Research

and Evaluation Center (SMITREC), University of Michigan,

Ann Arbor, MI, USA

\section{A. S. Zawadzki}

Department of Emergency Medicine,

Medical University of Warsaw,

Warsaw, Poland

R. Cunningham $(\bowtie)$

Injury Research Center, University of Michigan,

24 Frank Lloyd Wright, Suite H-3200, P.O. Box 443, Ann Arbor, MI 48106, USA

e-mail: stroh@umich.edu information on trauma and alcohol in Poland, a country undergoing unprecedented economic and cultural changes stemming from entry into the European Union (EU) in the midst of a global recession.

Results Injury is the third leading cause of death in Poland. Rates for all injuries in Poland are higher than in the rest of the EU. Alcohol is one of the greatest risk factors for disease and injury among men and one of the top ten health and injury risk factors for women. In this paper we review the last 10 years of research on injury and alcohol in Poland.

Conclusion Recommendations are provided for next steps with regard to training health care professionals in emergency medical settings to address this serious and growing problem.

Keywords Alcohol · Poland - Emergency department . Injury $\cdot$ Alcohol screening $\cdot$ Brief intervention

\section{Introduction}

Alcohol plays a significant role in accidents, injuries, and their outcomes. According to the World Health Organization (WHO), there are 76.3 million people with alcohol use disorders worldwide; in 2000, 1.8 million deaths and loss of 58.3 million disability-adjusted life years were attributed to alcohol [1]. Although the association between alcohol consumption and trauma-related morbidity and mortality is well-documented, particularly in the US, there is much less data on trauma and alcohol in Poland and other Eastern European countries.

In this paper we systematically review and summarize findings of the research published in the last 10 years on injury and alcohol in Poland. First, we provide a summary of alcohol consumption rates in Poland. Then, we summarize research on alcohol-related injuries, focusing on 
intentional and unintentional injuries. Finally, we suggest recommendations for future training in emergency medical settings to address this serious and growing problem.

\section{Methods}

A comprehensive search of Polish- and English-language journal articles was conducted using electronic databases including PubMed and MEDLINE, and web-based sources such as eMedicine. Additional information such as statistics related to injury and alcohol consumption was derived from Polish governmental and police publications, the World Health Organization (WHO), and Organization for Economic Co-operation and Development (OECD) reports. The search was conducted using the following keywords: alcohol/ethanol, Poland, trauma, injury, violence, traffic, suicide, gender, and alcohol consumption. From PubMed and MEDLINE searches, a total of 73 journal articles were examined. Thirty-one articles were found to fit the criteria, and 42 articles were excluded because they focused on alcohol as a risk factor for other health problems such as stroke, cancer, or cardiovascular disease. Three articles were added to the review from citations found in the original search. Hence, a total of 34 articles were included in the systematic review.

\section{Results}

Epidemiology of alcohol consumption in Poland

Moskalewicz presented five indicators of the increase in alcohol consumption immediately following the privatization of the alcohol industry in the late 1980s: increases in the rates of hospital admissions for alcoholic psychoses, hospital admissions due to alcohol dependence, psychiatric hospital admissions due to alcohol-related disorders (dependence and psychosis), increase in the rate of liver cirrhosis mortality, and increasing alcohol-related road accidents [2]. Alcohol sales data show that consumption leveled off in the late 1990s, but has been increasing since the beginning of this century [3]. Although distilled spirits and liquor are the preferred alcoholic beverages in Poland, beer consumption has steadily increased [4, 5]. In 2003, beer consumed in pure alcohol units was 3.951 per capita, and spirits consumed in pure alcohol units was 1.31 per capita [6]. The region of central and Eastern Europe has among the highest levels of alcohol consumption in the world [7].

Russia was found to have the most detrimental drinking patterns compared to EU Member States such as Hungary, Lithuania, Poland, and the Czech Republic, while the Czech Republic had the highest overall beer consumption levels in Europe, but a relatively less detrimental pattern of drinking [4]. The estimated average pattern of drinking of 1-4 drinks, with 4 being the most detrimental pattern and mainly based on heavy drinking and drinking to intoxication per occasion [4]. France and Sweden were found to differ both in volume of alcohol consumption and in drinking patterns, and the UK was found to have a beerdrinking culture, with a rise in heavy irregular drinking in recent years [4].

Recently published research based on surveys and data from the World Health Organization (WHO) establishes yearly premature alcohol-attributable traumatic deaths in adolescents in Poland at over 6,000, with 4,610 unintentional and 1,478 intentional injuries [4]. All alcoholattributable deaths in Poland are estimated at about 11,000 cases a year with a death rate of 8.7 per 10,000 for males and 0.9 per 10,000 for females [4]. Although comparable to other Eastern European countries, it is higher than in other Western European countries, such as Sweden, which has 2.7 and 0.5 deaths per 10,000 for men and women, respectively, and in the US, which is estimated to have a total overall death rate per 10,000 of 2.7 [8]. In 2007, the standarized death rate (SDR, per 100,000 people) in Poland was 13.45 for motor vehicle traffic accidents, 15.73 for suicide and intentional self-harm injuries, and 1.31 for homicide and assaults; however, statistics on how many of these deaths are attributed to alcohol are not available [9].

Hospital-based data illustrate a high burden of heavy drinking and alcohol dependence in Poland. In a primary care study, nearly $64 \%(\mathrm{~N}=4,373)$ of patients seeking routine health care had consumed alcohol in the previous 3 months [10]. Of these, 19\% were dependent drinkers (three or more positive CAGE responses [11] and/or those who consumed five or more drinks per day), about $36 \%$ of men reported more than 21 drinks per week, and about $21 \%$ of women had more than 14 drinks per week [10].

Studies show differences in alcohol consumption by gender, age, education, and region within Poland. Polish men report heavier drinking than women [4, 7, 12-16]. Rehm et al. found that $38.5 \%$ of men and $9 \%$ of women consumed an average of more than 3-4 drinks/day ( $>40 \mathrm{~g} /$ day), while $16.4 \%$ of men and $34.3 \%$ of women consumed very little or were abstinent [4]. In another study, almost $50 \%$ of alcohol-dependent patients $(\mathrm{N}=458)$ aged $18-64$ reported drinking more than 4 times/week [17]. Beer was the most frequently used beverage $(67.4 \%)$, followed by vodka $(63.2 \%)$ and wine (39.5\%). Studies report that higher education among women is related to increased alcohol consumption $[13,15,18]$, and women living in central/ urban settings may consume as much as $50 \%$ more than women in rural settings [13].

Similar to other countries, including the US, a large percentage of the youth engage in hazardous drinking 
patterns, such as binge drinking [19-22]. Among 15-16year-old students in 35 European countries, heavy episodic drinking during the past 30 days increased between 19951999 and between 2003-2007, especially among girls [19]. Between 2003-2007, the proportion of students reporting heavy episodic drinking during the past 30 days increased by $16 \%$ in Poland, while the highest increase of $31 \%$ occurred in Portugal [19]. Binge drinking is common among high school youth in the US who drink alcohol [20]. Men in the US are more likely to report binge drinking than women [21], and in 2006, binge and heavy drinking were highest for the 18- to 25-year-old group compared to other age groups, with the peak rate occurring at 21-23 years [22].

Comparison of drinking rates among 15-16 years olds between European countries and the US shows that the US is a low consumption country by European standards [23]. Poland had a higher prevalence rate $(65 \%)$ of drinking in the past 30 days than the US (35\%), with the highest rate being in Austria (82\%). The percentage of young people in the US who reported binge drinking was lower (22\%) than all other European countries except Turkey (15\%) [23].

Screening of two Polish samples (18 years and older) seeking emergency services revealed males were more likely to be younger, be injured, and meet criteria for alcohol use disorders than females. Among those who drank, males were more likely to report weekly drinking and $5+$ drinks on an occasion than women, and nearly $50 \%$ of young women reported binge drinking [17].

There is also a higher incidence of reported alcoholrelated mortality in men compared to women [4, 13], and more alcohol-related problems (such as difficulties with marriage/partner, friends/social life, work, physical and mental health, finance, police and other authorities) [12]. Although few studies in Poland have addressed psychosocial factors associated with alcohol misuse, one study found that a perceived imbalance in the effort-to-reward ratio at work was associated with binge drinking, increased overall alcohol intake, and problem drinking [24].

Patterns of alcohol use among adolescents have changed as well. A study of alcohol consumption among adolescents found that rates of heavy drinking increased between 1988 and 2004 [25]. In this study, both the type and quantity of alcohol consumed increased, reflecting shifts in the political, economic and cultural environment [25].

\section{Alcohol and injury in Poland}

With the rapid development of hospital Emergency Departments (EDs) and Emergency Medicine as a specialty in Poland [26], more data are becoming available on the extent of alcohol-related injuries. Injury is the third leading cause of death in Poland [27]. Rates for all injuries (intentional and unintentional) in Poland are higher than in the rest of the European Union (EU) [27]. Alcohol is one of the top ten health and injury risk factors for men and women [28]. A number of studies conducted among injured ED/trauma patients in Poland have shown a positive association between alcohol consumption and injury [4, 14, 16, 29-31]. A case-crossover analysis of emergency services patients from Warsaw and Sosnowiec showed a four-fold risk of any injury for those drinking within 6 $\mathrm{h}$ compared to those who had not been drinking in both the samples [30]. Men are more likely than women to be injured from drinking directly prior to the injury [30]. Males who drank more than 121 of alcohol annually were 2.4 times more likely to sustain injuries than those who drank less than 121 annually [32]. Injured men were twice as likely to report drinking within $6 \mathrm{~h}$ before the injury event than non-injured men presenting to the ED [14]. Michalska et al. found alcohol intoxication to be a debilitating factor in prompt diagnosis, assessment, and treatment of cranio-cerebral injury [33].

Unintentional injury: alcohol-related

In addition to examining overall injury rates, it is important to determine patterns of unintentional and intentional injury to be able to develop strategies to best deal with the complex interaction of alcohol and injury in the region. Unintentional injury is the fourth leading cause $(12.8 \%)$ of disability in males and seventh leading cause in females $(4.8 \%)$ in Poland [28]. WHO/Europe and the European Commission noted that the leading causes of unintentional injury death are transportation injuries, followed by falls, poisoning, drowning, and fires [27].

\section{Non-traffic-related injuries}

There are very few studies conducted in Poland that focus on unintentional injuries other than traffic injuries. One study examined 1,199 patients (14-79 years) visiting the Department of Surgery at a University Hospital in Krakow from 1987-2000 for treatment of hand injuries [34]. Of those, 320 patients $(26.7 \%)$ were found to be under the influence of alcohol at the time of injury, and most of them (89.3\%) were males and manual workers (74.3\%) [35]. Around $48.4 \%$ of patients suffered from injuries caused by a cut with glass, and 5.6\% had operated various kinds of machines and mechanical equipment under the influence of alcohol. Most accidents happened at home $(65.9 \%)$, while the others occurred in public places $(15.9 \%)$, in the street $(11.8 \%)$, on a farm $(3.1 \%)$, and at the workplace $(1.25 \%)$. Autopsies done in a study investigating the cause of mortality among Polish small-scale fishermen during a 40year period reports finding $>0.5 \%(0.5 \mathrm{~g} / \mathrm{l})$ blood alcohol 
levels in $45 \%$ of deaths out of the 82 cases where autopsy was carried out $(\mathrm{N}=177)$ [36]. Alcohol use was identified in 7 sea catastrophe-related cases and in 30 cases connected with other reasons for drowning with the greatest risk related to mooring, hauling, and boarding the nets. The authors report that alcohol may be implicated in at least one-quarter of the accidents and may have contributed to other factors, such as loss of balance on deck and injury preceding falling or being swept overboard.

\section{Traffic-related injuries}

In 2003, $11 \%$ of all traffic accidents in Poland were attributed to alcohol; alcohol was associated with death in $13 \%$ of all traffic-related mortalities [37]. Police reports revealed 167,318 drunk-driving cases in 2003 , out of which 18,830 of the drivers had a BAC of $0.2-0.5 \mathrm{ml} / \mathrm{g}$, while $148,488 \mathrm{had}$ a BAC of more than $0.5 \mathrm{ml} / \mathrm{g}$ [37]. The study at the University Hospital in Krakow from 1987-2000 reported that $7.1 \%(\mathrm{~N}=320)$ of those found to be under the influence of alcohol at the time of treatment for hand injuries were injured in traffic accidents [35].

Intentional injury: alcohol-related (non-suicidal)

The rates of homicide in Poland are higher than in the rest of the EU [27]. Intentional injury is also the sixth leading cause $(4.8 \%)$ of disability in males [28]. Studies conducted specifically in Poland, as well as those conducted across several other countries, have shown that alcohol consumption often precedes violent events [30, 38-41]. In samples of ED patients from Warsaw and Sosnowiec, Poland, Cherpitel et al. (2005) found that there was over a 17-fold increased risk for a violence-related injury for individuals who reported drinking $6 \mathrm{~h}$ before the injury, the risk being greater for women than for men [30]. An epidemiological investigation of the prevalence of potentially traumatic events (PTEs) in a sample of alcohol-dependent patients in Poland found that the numbers of PTEs reported were related to higher post-traumatic stress, but not necessarily to higher alcohol use intensity. A higher level of alcohol misuse was associated with two categories of PTEs: robbery and mugging, and witnessing death or assault [42].

Alcohol has been found to be a strong risk factor for intimate partner violence in Poland. Makara-Studzinska et al. analyzed data from a survey of 800 participants (400 perpetrators and their 400 victims of domestic violence) in the office of the Association for Violence Prevention in the city of Lublin, Poland [38]. Results suggested that perpetrators with a history of alcohol abuse were more likely to be younger, had less education, were less likely to be permanently employed, and had more problems with the legal system than perpetrators without a history of alcohol abuse. In the same sample, $76 \%$ of domestic violence perpetrators had problems related to alcohol, as measured by an AUDIT score $>8$ [38].

In addition, another study in the country found $25 \%$ of surveyed pregnant women reported physical and emotional abuse by their partners [43]. Men that physically abused pregnant women in this study were more often found to have primary school education, be unemployed, and drink alcohol. A substantial number of 15 to 20 year olds in Poland reported having experienced at least one of four kinds of parent-child violence (emotional, physical, negligence, and sexual abuse), of which parental alcohol abuse was one of the most frequently cited reasons for family violence [44].

\section{Alcohol and suicide}

In Poland, suicide is the leading cause of intentional injuryrelated death, and suicide rates are higher than in the rest of the EU [27]. From 1989 to 1994, a time of rapid social and political change, the suicide rate in Poland increased by 26.5\% [45]. The study aimed at describing suicide mortality in Eastern Europe by investigating the covariation between changes in some of the hypothesized causes such as alcohol consumption, economic situation, general social stress, political situation, societal (dis)organization, and the changes in the suicide rates. The linear regression model, which consisted of variables such as hypothetical general stress (as indicated by mortality/life expectancy), democratization, alcohol consumption, and social disorganization (with a period-dependent effect), was able to predict percentual changes in the suicide rates in 16 out of the 28 Eastern Bloc countries from 1984-1989 and 1989-1994 fairly accurately, but failed to do so for Poland besides other countries [45]. On the other hand, Landberg (2008) noted that the relationship between alcohol consumption and suicide mortality tends to be strongest in countries with detrimental drinking patterns, such as Poland (based on WHO's hazardous patterns score) [46]. In this cross-cultural study that included Poland, a 1-1 increase in per capita consumption of alcohol was associated with an increase in overall suicide rates by $5.7-7.5 \%$, with males at higher risk than females [46]. In another study, among 154 alcoholdependent patients admitted to addiction treatment centers in Poland, $43 \%$ reported attempting suicide at some point during their lifetime [47]. Post-mortem reports have shown the presence of alcohol in almost $50 \%$ of Polish suicide victims [48].

Training recommendations

Given the strong association between alcohol consumption and injury in Poland, it is imperative that medical 
professionals be prepared to respond. Academic Emergency Departments, the Polish Emergency Medicine Society, and Psychology and Social Service Societies, among other entities, will be key in the development and delivery of training materials to emergency, primary care, social service, and addiction treatment professionals. Based on training recommendations for the US and other countries, training of current and future ED physicians, nurses, EMTs, social workers, and psychologists in Poland and Eastern Europe in general should include the following areas:

\section{Recognition and Assessment}

To ensure that clinicians are knowledgeable in assessing the quantity and frequency of alcohol and other drug use among patients seen in medical and social service settings, key recommendations include: (1) increasing preclinical and clinical training regarding (a) the available alcohol screening instruments; (b) methods to determine other medication and drug use [including over-the-counter (OTC) medications and herbal agents]; (c) techniques for conducting screening; (d) techniques to incorporate structured screening for alcohol, medications, and illicit drugs into standard emergency practice; and (2) developing preclinical and clinical training evaluations and tests that include questions on substance use screening.

A study comparing performance of alcohol screening instruments to identify alcohol use disorders in the emergency services setting in the Warsaw and Sosnowiec regions of Poland found sensitivity of the RAPS4 and Alcohol Use Disorders Identification Test (AUDIT) to be significantly better than the CAGE for alcohol dependence among males in Warsaw, but specificity to be poorer in males in both the samples [17]. The CAGE appeared to perform considerably better for both males and females in Sosnowiec than in Warsaw. Among females, sensitivity for alcohol abuse/harmful drinking and for alcohol dependence or abuse/harmful drinking was significantly better for the RAPS4-QF than for the CAGE or AUDIT at a cutoff point of 8 across both sites [17]. However, a smaller-scale research study found that the AUDIT questionnaire was more sensitive than the CAGE when implemented in Polish emergency departments [49]. This finding is supported by a number of studies in the US and UK in a variety of medical settings [50-53]. The AUDIT has been found to have good psychometric properties in a number of countries with a variety of patient populations.

\section{Conducting Structured and Targeted Brief Advice/ Interventions}

Advice and brief interventions can be delivered as part of early detection programs in EDs and other medical and psychosocial treatment settings. Brief alcohol interventions such as tailored or generic booklets with brief counseling or motivational interviewing with an interventionist have been proven to be effective in a variety of medical settings, including the Emergency Department [54-59]. Brief interventions have two purposes: (1) to help individuals who are classified as at-risk for alcohol problems to cut back or stop using alcohol or drugs, and (2) to help individuals with more serious substance use problems engage in needed treatment. Educational materials are available through the National Institute on Alcohol Abuse and Alcoholism (NIAAA) and through the Center for Substance Abuse Treatment (CSAT) in the Treatment Improvement Protocol (TIP) \#34, 'Brief Interventions and Brief Therapies for Substance Abuse'[60], as well as through the SBIRT (Screening, Brief Intervention, Referral, and Treatment) Quick Guide [61].

Training can be made available to professionals who work in emergency care, primary care, and psychosocial programs through preclinical and clinical education programs, continuing education credits, and other workshop opportunities. These are needed because, in a changing health care delivery system, brief, effective methods to deal with alcohol problems will be both clinically and cost effective. One such short, concentrated training session at Yale University ED in Connecticut significantly improved knowledge and practice of screening and interventions for alcohol problems among a sample of emergency medicine residents, while the control group at Harvard University in Massachusetts showed no changes [62]. There are very few preclinical and clinical programs that currently include any of the techniques of brief alcohol interventions in Poland.

Because the ED is a very fast-paced, clinically demanding venue, training personnel in how to identify and manage patients with at-risk and problem drinking should also be accompanied by research on methods to best implement some of the newer, innovative technologies for screening and intervening. The use of computerized tailored interventions represents one such technique to provide targeted, individualized feedback to injured and medical ED patients [54]. Other technologies that may be useful in the future in Poland include the use of interactive voice recognition (IVR) technology to facilitate screening, delivery of educational interventions, and follow-up on patient progress over the telephone. Interactive computer programs on laptops or palmtops; web-based interventions; computerized bundling of brief health messages for multiple health risks (e.g., smoking, alcohol use, seat belt use); and audio interventions tailored to specific problems and delivered through headsets are all potential approaches in emergency, urgent care, and primary care settings [63].

\section{Referral to Treatment}

Also, providers need to have knowledge of the available in- and outpatient programs to help those individuals who meet criteria for more serious substance use problems. The brief intervention structure provides the opportunity to 
work with patients who have more serious alcohol problems and to help them consider obtaining formal substance abuse treatment.

It is ideal to have psychiatric emergency services colocated in the ED with acute medical and injury care whenever possible to address patients who screen positive for risky alcohol use. Alternatively increased collaboration and consultation between ED and mental health services is critical to any successful screening and brief intervention program. However, specialty resources are limited and often cannot be provided during the acute care time frame. The training recommendations provided are focused on the many EDs and clinicians that do not have access or availability to provide this service by specialty psychiatric services.

\section{Conclusion}

The burden of alcohol-related injury will likely increase as Poland's economic and social structure continue to change resulting from admission to the $\mathrm{EU}$, changes in the employment structure, and coping with a global recession. Emergency departments need to be prepared to implement alcohol screening and intervention practices in order to effectively target and treat patients with substance use disorders and prevent future alcohol-associated re-injury, readmissions, and mortality. The health care delivery system in Poland must adopt new and innovative methods that work with a range of patient populations who have drinking patterns that put them at risk for intentional and unintentional injuries, problems related to physical and mental health functioning, employment, and social/family problems. Alcohol use and misuse in Poland, and Eastern Europe more generally, and the resulting burden of injuries have made it critically important to address this important public health concern by developing surveillance and prevention strategies to limit future morbidity and mortality. Knowledge gained from addressing alcohol problems in this strategically important region of the world can have wide-ranging implications for global health interventions and policies with regards to alcohol problems.

Acknowledgments The authors wish to acknowledge the National Institutes of Health International Fogarty Center and NIH Fogarty International Injury Fellowship for support in this work.

\section{References}

1. World Health Organization, Department of Mental Health and Substance Abuse (2004) Global status report on alcohol. Available via http://www.who.int/substance_abuse/publications/global_status report_2004_overview.pdf. Accessed September 242009
2. Moskalewicz J (1993) Privatization of the alcohol arena in Poland. Contemp Drug Prob 20(n2):263-275

3. The State Agency for Prevention of Alcohol Related Problems (PARPA) (2009) Basic trends pertaining to alcohol use in Poland. Available via http://fas.nazwa.pl/parpa_en/index.php?option= com content\&view $=$ article\&id $=52$ :basic-trends-pertaining-to- alcohol-use-in-poland $\&$ catid $=35$ : basic-polish-data $\&$ Itemid $=57$. Accessed June 242009

4. Rehm J, Sulkowska U, Manczuk M, Boffetta P, Powles J, Popova S, Zatonski W (2007) Alcohol accounts for a high proportion of premature mortality in central and eastern Europe. Int J Epidemiol 36(2):458-467

5. Rehn N, Room R, Edwards G (2001) Alcohol in the European Region-consumption, harm and policies. Available via http:// www.euro.who.int/document/E76240.pdf. Accessed September 242009

6. World Health Organization (2007) Basic statistics from the Health or All (HFA) database: Poland. Available via http://www.euro. who.int/alcoholdrugs/ctryinfo/HFAExtracts?Country=POL\&Ctry Name=Poland. Accessed September 222009

7. Popova S, Rehm J, Patra J, Zatonski W (2007) Comparing alcohol consumption in central and eastern Europe to other European countries. Alcohol Alcohol 42(5):465-473

8. National Center for Chronic Disease Prevention and Health Promotion Alcohol-related disease impact (ARDI) deaths report 2001-2005. Available via https://apps.nccd.cdc.gov/ardi/Home page.aspx. Accessed April 202009

9. World Health Organization (WHO), Regional office for Europe Mortality from selected causes of injury-last available year: Poland. Available via http://www.euro.who.int/violenceinjury/ ctryInfo/MortalityFromInjuries? Country $=$ POL \&CtryName $=$ Poland. Accessed September 252009

10. Manwell LB, Ignaczak M, Czabala JC (2002) Prevalence of tobacco and alcohol use disorders in Polish primary care settings. Eur J Public Health 12(2):139-144

11. Ewing JA (1984) Detecting alcoholism. The CAGE questionnaire. JAMA 252(14):1905-1907

12. Bobak M, Room R, Pikhart H, Kubinova R, Malyutina S, Pajak A, Kurilovitch S, Topor R, Nikitin Y, Marmot M (2004) Contribution of drinking patterns to differences in rates of alcohol related problems between three urban populations. J Epidemiol Community Health 58(3):238-242

13. Wojtyniak B, Moskalewicz J, Stokwiszewski J, Rabczenko D (2005) Gender-specific mortality associated with alcohol consumption in Poland in transition. Addiction 100(12):1779-1789

14. Cherpitel CJ, Moskalewicz J, Swiatkiewicz G (2004) Drinking patterns and problems in emergency services in Poland. Alcohol Alcohol 39(3):256-261

15. Stelmach W, Kaczmarczyk-Chalas K, Bielecki W, Drygas W (2004) The impact of income, education and health on lifestyle in a large urban population of Poland (Cindi programme). Int $\mathrm{J}$ Occup Med Environ Health 17(3):393-401

16. Sein Anand J, Chodorowski Z, Kujawska H, Korolkiewicz R, Stasiak M (2005) Various clinical aspects of alcohol consumption in trauma patients. Przegl Lek 62(6):365-367

17. Cherpitel CJ, Ye Y, Moskalewicz J, Swiatkiewicz G (2005) Screening for alcohol problems in two emergency service samples in Poland: comparison of the RAPS4, CAGE and AUDIT. Drug Alcohol Depend 80(2):201-207

18. Skrzypczak M, Szwed A, Pawlinska-Chmara R, Skrzypulec V (2008) Body mass index, waist to hip ratio and waist/height in adult Polish women in relation to their education, place of residence, smoking and alcohol consumption. HOMO 59 (4):329-342

19. Hibell B, Guttormsson U, Ahlström S, Balakireva O, Bjarnason T, Kokkevi A, Kraus L (2007) The 2007 ESPAD report. Substance use 
among students in 35 European countries. Available via http://www. espad.org/documents/Espad/ESPAD_reports/2007/The_2007 ESPAD_Report-FULL_091006.pdf. Accessed January 42009

20. Miller JW, Naimi TS, Brewer RD, Jones SE (2007) Binge drinking and associated health risk behaviors among high school students. Pediatrics 119(1):76-85

21. Naimi TS, Brewer RD, Mokdad A, Denny C, Serdula MK, Marks JS (2003) Binge drinking among US adults. JAMA 289(1):70-75

22. Substance Abuse and Mental Health Services Administration (2007) Results from the 2006 national survey on drug use and health: National findings. Available via http://www.oas.samhsa. gov/NSDUH/2K6NSDUH/2K6results.cfm. Accessed December 152009

23. U.S. Department of Justice, Office of Justice Programs, Office of Juvenile Justice and Delinquency Prevention (2003) Youth drinking rates and problems: A comparison of European countries and the United States. Available via http://www.udetc.org/documents/ CompareDrinkRate.pdf. Accessed

24. Bobak M, Pikhart H, Kubinova R, Malyutina S, Pajak A, Sebakova H, Topor-Madry R, Nikitin Y, Caan W, Marmot M (2005) The association between psychosocial characteristics at work and problem drinking: a cross-sectional study of men in three Eastern European urban populations. Occup Environ Med 62(8):546-550

25. Okulicz-Kozaryn K, Borucka A (2008) Warsaw adolescent alcohol use in a period of social change in Poland: cluster analyses of five consecutive surveys, 1988 to 2004. Addict Behav 33(3):439-450

26. Hargarten SW, Karlson T (1994) Motor vehicle crashes and seat belts: a study of emergency physician procedures, charges, and documentation. Ann Emerg Med 24(5):857-860

27. World Health Organization (2007) Progress in the prevention of injuries in the WHO European Region: Poland. Available via http://www.euro.who.int/document/VIP/poland.pdf. Accessed September 242009

28. World Health Organization (2006) Highlights on health in Poland 2005. Available via http://www.euro.who.int/document/e88745.pdf. Accessed September 242009

29. Cherpitel CJ, Bond J, Ye Y (2006) Alcohol and injury: a risk function analysis from the Emergency Room Collaborative Alcohol Analysis Project (ERCAAP). Eur Addict Res 12(1):42-52

30. Cherpitel CJ, Ye Y, Moskalewicz J, Swiatkiewicz G (2005) Risk of injury: a case-crossover analysis of injured emergency service patients in Poland. Alcohol Clin Exp Res 29(12):2181-2187

31. Cherpitel CJ, Ye Y, Bond J (2004) Alcohol and injury: multi-level analysis from the emergency room collaborative alcohol analysis project (ERCAAP). Alcohol Alcohol 39(6):552-558

32. Moskalewicz J, Swiatkiewicz G, Cherpitel CJ, Ye Y (2006) Results of two emergency room studies. Eur Addict Res 12(4):169-175

33. Michalska A, Berent $J$ (2007) Malpractice in diagnosis and treatment of craniocerebral injuries in cases reviewed by the Forensic Medicine Department, Medical University of Lodz. Neurol Neurochir Pol 41(4):327-332

34. Trybus M, Lorkowski J, Brongel L, Hladki W (2006) Causes and consequences of hand injuries. Am J Surg 192(1):52-57

35. Trybus M, Tusinski M, Guzik P (2005) Alcohol-related hand injuries. Injury 36(10):1237-1240

36. Jaremin B, Kotulak E (2004) Mortality in the Polish small-scale fishing industry. Occup Med 54(4):258-260

37. Buttler I (2005) Road accidents in Poland. IATSS Research 29 (1):102-105

38. Makara-Studzinska M, Gustaw K (2007) Intimate partner violence by men abusing and non-abusing alcohol in Poland. Int J Environ Res Public Health 4(1):76-80

39. Cherpitel CJ, Ye Y, Bond J (2005) Attributable risk of injury associated with alcohol use: cross-national data from the emergency room collaborative alcohol analysis project. Am J Public Health 95 (2):266-272

40. Borges G, Cherpitel CJ, Orozco R, Bond J, Ye Y, Macdonald S, Giesbrecht N, Stockwell T, Cremonte M, Moskalewicz J, Swiatkiewicz G, Poznyak V (2006) Acute alcohol use and the risk of non-fatal injury in sixteen countries. Addiction 101 (7):993-1002

41. Wells S, Thompson JM, Cherpitel C, Macdonald S, Marais S, Borges $G$ (2007) Gender differences in the relationship between alcohol and violent injury: an analysis of cross-national emergency department data. J Stud Alcohol Drugs 68(6):824-833

42. Dragan M, Lis-Turlejska M (2007) Lifetime exposure to potentially traumatic events in a sample of alcohol-dependent patients in Poland. J Trauma Stress 20(6):1041-1051

43. Kramek J, Grzymala-Krzyzostaniak A, Celewicz Z, RoninWalknowska E (2001) Violence towards pregnant women. Ginekol Pol 72(12):1042-1048

44. Latalski M, Skorzynska H, Pacian A, Sokol M (2004) Intensification of the phenomenon of violence in the family environment of teenagers. Ann Univ Mariae Curie Sklodowska Med 59(1):467-473

45. Makinen IH (2000) Eastern European transition and suicide mortality. Soc Sci Med 51(9):1405-1420

46. Landberg J (2008) Alcohol and suicide in eastern Europe. Drug Alcohol Rev 27(4):361-373

47. Wojnar M, Ilgen MA, Jakubczyk A, Wnorowska A, Klimkiewicz A, Brower KJ (2008) Impulsive suicide attempts predict posttreatment relapse in alcohol-dependent patients. Drug Alcohol Depend 97(3):268-275

48. Polewka A, Bolechala F, Kolodziej J, Chrostek Maj J, Groszek B, Trela F, Forys Z (2005) Suicide and suicide attempts in adolescents and young adults in Krakow in the years 2002-2003. Przegl Lek 62 (6): $422-426$

49. Sein Anand J, Chodorowski Z, Kujawska-Danecka H, Ciechanowicz $\mathrm{R}$ (2007) Patients with alcohol problem in the Emergency Department of Medical University of Gdańsk. Przegl Lek 64(45):236-237

50. Philpot M, Pearson N, Petratou V, Dayanandan R, Silverman M, Marshall J (2003) Screening for problem drinking in older people referred to a mental health service: a comparison of CAGE and AUDIT. Aging Ment Health 7(3):171-175

51. McCusker MT, Basquille J, Khwaja M, Murray-Lyon IM, Catalan J (2002) Hazardous and harmful drinking: a comparison of the AUDIT and CAGE screening questionnaires. QJM 95(9):591-595

52. Cook RL, Chung T, Kelly TM, Clark DB (2005) Alcohol screening in young persons attending a sexually transmitted disease clinic. Comparison of AUDIT, CRAFFT, and CAGE instruments. J Gen Intern Med 20(1):1-6

53. Knight JR, Sherritt L, Harris SK, Gates EC, Chang G (2003) Validity of brief alcohol screening tests among adolescents: a comparison of the AUDIT, POSIT, CAGE, and CRAFFT. Alcohol Clin Exp Res 27(1):67-73

54. Blow FC, Barry KL, Walton MA, Maio RF, Chermack ST, Bingham CR, Ignacio RV, Strecher VJ (2006) The efficacy of two brief intervention strategies among injured, at-risk drinkers in the emergency department: impact of tailored messaging and brief advice. J Stud Alcohol 67(4):568-578

55. Havard A, Shakeshaft A, Sanson-Fisher R (2008) Systematic review and meta-analyses of strategies targeting alcohol problems in emergency departments: interventions reduce alcohol-related injuries. Addiction 103(3):368-376, discussion 377-8

56. D'Onofrio G, Degutis LC (2002) Preventive care in the emergency department: screening and brief intervention for alcohol problems in the emergency department: a systematic review. Acad Emerg Med 9(6):627-638

57. Monti PM, Colby SM, Barnett NP, Spirito A, Rohsenow DJ, Myers M, Woolard R, Lewander W (1999) Brief intervention for 
harm reduction with alcohol-positive older adolescents in a hospital emergency department. J Consult Clin Psychol 67 (6):989-994

58. Hungerford DW, Pollock DA, Todd KH (2000) Acceptability of emergency department-based screening and brief intervention for alcohol problems. Acad Emerg Med 7(12):1383-1392

59. Longabaugh R, Woolard RE, Nirenberg TD, Minugh AP, Becker B, Clifford PR, Carty K, Licsw SF, Gogineni A (2001) Evaluating the effects of a brief motivational intervention for injured drinkers in the emergency department. J Stud Alcohol 62 (6):806-816

60. Barry KL (1999) Brief interventions and brief therapies for substance abuse. Treatment Improvement Protocol (TIP) Series 34. Available via http://ncadi.samhsa.gov/govpubs/BKD341/. Accessed September 242009

61. U.S. Department of Health and Human Services, Substance Abuse and Mental Health Service Administration, Center for Substance Abuse Treatment (2007) Alcohol screening and brief intervention (SBI) for trauma patients: Committee on trauma quick guide. Available via http://sbirt.samhsa.gov/documents/SBIRT_guide_Sep07.pdf. Accessed April 82008

62. D'Onofrio G, Nadel ES, Degutis LC, Sullivan LM, Casper K, Bernstein E, Samet JH (2002) Improving emergency medicine residents' approach to patients with alcohol problems: a controlled educational trial. Ann Emerg Med 40(1):50-62
63. Barry KL (2002) Intervening with alcohol problems in emergency medicine: Discussion of DiClemente and Soderstrom. In: Hungerford DW, Pollock DA (eds) Alcohol problems among Emergency Department patients. Available via http://www.cdc.gov/Ncipc/ pub-res/alcohol proceedings/Session3-PDF.pdf. Accessed September 242009

Piotr Wozniak M.D. Born on 18 January 1976 in Gdynia, Poland, is an Emergency Medicine Resident Doctor working in St. Adalbert Hospital Emergency Department in Gdansk, Poland. He is a member of the Polish Society for Emergency Medicine. From November 2008 to May 2009, he was a Research Fellow within the Fogarty International Injury and Alcohol Research Program at the University of Michigan, Department of Psychiatry, Ann Arbor, MI.

He graduated in 2003 from the Medical University of Gdansk, Faculty of Medicine, with an MD degree. During the undergraduate period from 2000 to 2003, he was a leader of the Student Scientific Group of Emergency Medicine. In 2004, he was a visiting student at Duke University School of Medicine, Durham, NC.

Now working at the Hospital ED and as a Junior Emergency Physician in the Emergency Medicine Ambulance Service in Sopot, Poland, he is interested in associations between alcohol consumption and injury occurence among ED patients. 